\title{
Seed Production Enhanced by Antiauxin in the pat-2 Parthenocarpic Tomato Mutant
}

\author{
Masahumi Johkan', Tomoko Chiba, Kazuhiko Mitsukuri, Satoshi Yamasaki, Hideyuki Tanaka, \\ Kei-ichiro Mishiba, Toshinobu Morikawa, and Masayuki Oda² \\ Graduate School of Life and Environmental Sciences, Osaka Prefecture University, Sakai, 599-8531, \\ Japan
}

Chihiro Yamamoto

School of Life and Environmental Sciences, Osaka Prefecture University, Sakai, 599-8531, Japan

Hiroshi Ohkawa
Aichi-ken Agricultural Research Center, Aichi, 480-1193, Japan

AdDitional InDEX words. auxin, p-chlorophenoxyisobutyric acid, ovule development, pollen tube elongation, seed formation, Solanum lycopersicum

\begin{abstract}
Aвstract. There is concern that high temperatures resulting from global warming could reduce fruit set of tomato (Solanum lycopersicum). However, fruit set of parthenocarpic tomato genotypes, which often bears seedless fruit, is not reduced when grown under a high temperature. The cause of seedless fruit development was studied with the aim of increasing the seed number in parthenocarpic tomato. Ovule number at anthesis in parthenocarpic and nonparthenocarpic fruit did not differ, but the proportion of undeveloped ovules increased with time after anthesis in parthenocarpic tomato, whereas most ovules in non-parthenocarpic tomato developed normally. Pollen grains germinated on the stigma and extruded pollen tubes in parthenocarpic and non-parthenocarpic tomatoes, but in parthenocarpic tomato, pollen tube elongation was markedly inhibited in the style base. Elongation of pollen tubes on agar containing indoleacetic acid (IAA) was depressed in parthenocarpic and non-parthenocarpic tomato plants. p-Chlorophenoxyisobutyric acid (PCIB), which inhibits auxin action, did not affect the fruit set and fresh weight in either type of tomato, although seed number per fruit in parthenocarpic tomato was significantly increased from $13 \pm 2$ to $74 \pm 6$ seeds by PCIB treatment. These results indicated that a high IAA concentration in the ovary of parthenocarpic tomato inhibited pollen tube elongation, and that poor fertilization resulted in failure of ovule development. Moreover, floral organs in parthenocarpic tomato were normally developed as in non-parthenocarpic tomato, and seed development could be induced in parthenocarpic tomato by PCIB treatment.
\end{abstract}

Global warming threatens agricultural production. In plants, reproductive development is more sensitive to high temperature stress than vegetative development, and the sensitivity to high temperature stress appears to differ among crops (Sato et al., 2006). In tomato, the optimal temperature for fruit set was reported as 21 to $24{ }^{\circ} \mathrm{C}$ (Geisenberg and Stewart, 1986) and 22 to $25^{\circ} \mathrm{C}$ (Peet and Bartholomew, 1996). In addition, Sato et al. $(2002,2006)$ reported that pollen viability and release were affected adversely by high temperature and became major limiting factors for fruit set in tomato.

In general, the development of fruit occurs following pollination and fertilization, and coincides with maturation of the seeds (Gorguet et al., 2005). Parthenocarpy is the phenomenon by which fruit set is induced by plant growth regulators, mainly auxin and gibberellins (GAs), without pollination and fertilization, and parthenocarpic fruit can develop in harsh environments (Srivastava and Handa, 2005). In non-parthenocarpic tomato, failure of fruit set occurs under unfavorable environmental conditions such as high temperatures (George et al., 1984). Therefore, a tomato cultivar with the parthenocarpic phenotype has the potential for achieving improved yields under global warming.

Received for publication 4 Sept. 2009. Accepted for publication 18 Nov. 2009. ${ }^{1}$ Current address: Environmental Science Research Laboratory, Central Research Institute of Electric Power Industry, Abiko, 270-1194, Japan.

${ }^{2}$ Corresponding author. E-mail: moda@plant.osakafu-u.ac.jp.
Genetic parthenocarpy in tomato is the result of expression of the pat, pat-2, or pat-3/pat-4 genes (Ficcadenti et al., 1999; Fos and Nuez, 1996, 1997; George et al., 1984; Gorguet et al., 2005; Lukyanenko, 1991; Mazzucato et al., 1998). The parthenocarpic tomato underlying pat genes have been studied, namely development of flower tissue with pat (Mazzucato et al., 1998, 2003) or pat-2 genes (Kataoka et al., 2003), and the role of endogenous hormones with pat-2 (Fos et al., 2000; Kataoka et al., 2004) or pat-3/pat-4 (Fos et al., 2001), or polyamines with pat-2 (Fos et al., 2003). Seedless fruit or fruit with fewer seeds in tomato was induced genetically (Fos et al., 2000, 2001; Mazzucato et al., 1998) or artificially, that is, auxin and GAs (Hamamoto et al., 1998; Koshioka et al., 1994; Serrani et al., 2007), but the cause of seedless or fewer seeds is not clear. Elucidation of the seedless mechanism is necessary to produce seeds of parthenocarpic cultivars for their sexual reproduction.

Fertilization requires pollen germination, and penetration and elongation of pollen tubes in stylar tissue toward the embryo sac for double fertilization to occur. Mazzucato et al. (2003) reported that pollen tubes appeared to become disorientated in the ovarian cavity and often failed to adhere to the placental surface in the pat tomato mutant. It has been suggested that parthenocarpy may be the result of elevated hormone levels in the ovary even in the absence of pollination and fertilization (Gillaspy et al., 1993; Nitsch, 1970). Our hypothesis was that a high concentration of endogenous auxin 
in the parthenocarpic ovary may inhibit pollen tube growth in the lower style and thus prevent fertilization. Therefore, we investigated pollen tube elongation in the style and ovule development in the ovary of pat-2 parthenocarpic tomato. In addition, the effect of a range of concentrations of auxin (IAA) on pollen tube elongation was studied. The results contribute to our understanding of the mechanism controlling seed number in pat-2 parthenocarpic tomato.

\section{Materials and Methods}

Plant materials. A parthenocarpic tomato carrying the pat-2 gene, cultivar Renaissance (Sakata Seed, Yokohama, Japan) that has large fruit and was readily available from commercial sources and a non-parthenocarpic tomato, cultivar Momotaro (Takii Seed, Kyoto, Japan) that also has large fruit were used in the experiments.

Tomato seeds of each cultivar were pregerminated for $3 \mathrm{~d}$ at $25{ }^{\circ} \mathrm{C}$ under dark conditions. Germinated seeds were sown in a 72 -cell tray ( $50 \mathrm{~mL}$ per cell) filled with a mixture of peatmoss and vermiculite $(2: 1, \mathrm{v} / \mathrm{v})$. At $30 \mathrm{~d}$ after sowing, the seedlings were transplanted to 6 -cm-diameter plastic pots filled with the same substrate, and were transplanted again to 20 -cm-diamer pots at $50 \mathrm{~d}$ after sowing. The plants were grown in a greenhouse at Osaka Prefecture University (Sakai, Japan). A nutrient solution containing (in $\left.\mathrm{mmol} \cdot \mathrm{L}^{-1}\right) 4.6 \mathrm{~N}\left(4.1 \mathrm{NO}^{3-}, 0.4 \mathrm{NH}_{4}^{+}\right), 1.3$ $\mathrm{P}, 2.2 \mathrm{~K}, 1.1 \mathrm{Ca}$, and $0.4 \mathrm{Mg}$ was applied from April to October and $9.2 \mathrm{~N}\left(8.2 \mathrm{NO}^{3-}, 0.8 \mathrm{NH}_{4}^{+}\right), 2.6 \mathrm{P}, 4.4 \mathrm{~K}, 2.2 \mathrm{Ca}$, and $0.8 \mathrm{Mg}$ was applied from November to March. The plants were staked and all lateral shoots were removed while less than $1 \mathrm{~cm}$ in length.

Ovule DeVelopment AFTer POLlination. All tomato seeds were sown on 20 Aug. 2004 and cultivated at $33.4 / 24.5{ }^{\circ} \mathrm{C}$ (maximum/minimum temperature) in the greenhouse. Five to 10 flowers per plant that opened between 13 and 15 Oct. were emasculated before anthesis, and five flowers per plant were artificially self-pollinated at anthesis. Twenty self-pollinated ovaries were sampled 0, 1, 2 and 3 weeks after anthesis, respectively, and were fixed, dehydrated, and stained according to Johkan et al. (2008). Ovary transverse sections (12 or $20 \mu \mathrm{m}$ thick) were observed by light microscopy (BX-50; Olympus, Tokyo), and the number of ovules were counted in 15 ovaries. Seed number and fruit fresh weight in 30 mature fruit were also measured.

Pollen tube elongation in Style. All tomato seeds were sown on 16 Apr. 2004 and cultivated at $28.9 / 16.4{ }^{\circ} \mathrm{C}$ (maximum/ minimum temperature) in the greenhouse. Five to 15 flowers per plant that opened between 5 and 7 June were emasculated before anthesis, and five flowers per plant were artificially pollinated. Twenty styles were sampled $72 \mathrm{~h}$ after pollination and were then fixed. After fixation, the styles were embedded in an $8 \%$ agar block. Transverse sections $200 \mu \mathrm{m}$ thick, each including the four style sections distinguished (Fig. 1), were prepared with a vibrating blade microtome (VIB-1500; Vibratome, St. Louis), stained with aniline blue, and observed with fluorescence microscopy (BX-50; Olympus). Areas of the pollen tube in five styles per three replications were digitized with Image software (Scion, Frederick, MD), and the arrival rate of pollen tubes in each style region was expressed as a percentage of that in the S1 area (Fig. 1).
EFFECT OF INDOLEACETIC ACID ON POLlen TUBE ELONGATION. All tomato seeds were sown on 23 Aug. 2006 and cultivated at 33.1/15.1 ${ }^{\circ} \mathrm{C}$ (maximum/minimum temperature) in the greenhouse. Anthers per 10 flowers were sampled on 24 Oct. and dried overnight. Pollen grains were incubated on $0.8 \%$ agar containing $3 \%$ sucrose and $0,0.1,1$, or $10 \mathrm{mg} \cdot \mathrm{L}^{-1}$ IAA at $25^{\circ} \mathrm{C}$, and 10 pollen tube length in five replications was observed by light microscopy (BX-50; Olympus).

EFFECT OF $P$-CHLOROPHENOXYISOBUTYRIC ACID ON SEED SET IN PARTHENOCARPIC FRUIT. All tomato seeds were sown on 4 Sept. 2007 and cultivated at $32.4 / 16.6{ }^{\circ} \mathrm{C}$ (maximum/minimum temperature) in the greenhouse. Five to 10 flowers of the parthenocarpic tomato were dipped in 0 or $100 \mathrm{mg} \cdot \mathrm{L}^{-1} \mathrm{PCIB}$ $7 \mathrm{~d}$ before anthesis. The PCIB-treated flowers that opened between 3 and 10 Nov. were emasculated before anthesis and five flowers per plant were artificially pollinated. Fruit set per all pollinated flower, fruit fresh weight, seed set per all fruit and seed numbers in all fruit contained with seeds and without seeds were counted in 30 mature fruit.

Statistical analysis. The difference between two independent means was tested with Student's $t$ test at the $0.05,0.01$, and 0.001 significance levels. Tukey's multiple range tests were used to test the difference between more than two means at the 0.05 significance level using statistics software (MEPHAS; Osaka University, Suita, Japan).

\section{Results}

Ovule DeVElopment AFTER POLlination. The average numbers of ovules per fruit at anthesis and fruit fresh weight were not significantly different between the parthenocarpic and

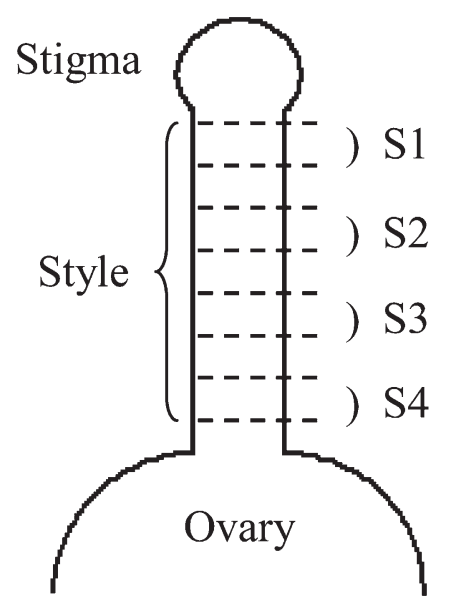

Fig. 1. Definition of S1 to S4 regions of the style in tomato. Four regions in the style were recognized to evaluate pollen tube elongation in the style.

Table 1. Fruit fresh weight and number of ovules and seeds per fruit in non-parthenocarpic and parthenocarpic tomato plants.

\begin{tabular}{lccc}
\hline Type & $\begin{array}{c}\text { Fruit fresh wt } \\
{[\text { mean } \pm \mathrm{SE}(\mathrm{g})]}\end{array}$ & $\begin{array}{c}\text { Ovules } \\
{[\text { mean } \pm \mathrm{SE}(\text { no./fruit })]}\end{array}$ & $\begin{array}{c}\text { Seeds } \\
{[\text { mean } \pm \text { SE (no./fruit)] }}\end{array}$ \\
\hline Non-parthenocarpy & $211 \pm 3$ & $202 \pm 7$ & $191 \pm 1$ \\
Parthenocarpy & $207 \pm 1$ & $173 \pm 1$ & $31 \pm 5$ \\
$t$ test & NS & NS & $* * *$
\end{tabular}

*** different at 0.001 significance level as indicated by Student's $t$ test; NS = not significantly different at 0.05 level. 
non-parthenocarpic tomato cultivars (Table 1). However, the number of seeds per fruit was significantly lower in parthenocarpic tomato than that in non-parthenocarpic tomato, whereas fruit fresh weight was not significantly different between the cultivars.

To investigate the inhibition of seed development in parthenocarpic tomato, ovules were observed at various developmental stages in parthenocarpic and non-parthenocarpic tomato (Fig. 2). The ovules in both types of tomato were normal at 0 and 1 week after anthesis (Fig. 2, A-D). At 2 and 3 weeks after anthesis, undeveloped ovules were observed in parthenocarpic tomato (Fig. 2, F and $\mathrm{H}$ ), whereas developing ovules were present in non-parthenocarpic tomato fruit (Fig. 2, E and G).

Ovule development was distinctly arrested in parthenocarpic tomato (Fig. 3). One week after anthesis, the proportion of developing ovules in parthenocarpic tomato was similar to that of non-parthenocarpic tomato. Two weeks after anthesis, however, the proportion of developing ovules in parthenocarpic tomato was significantly reduced to $55 \%$ compared with $94 \%$ in non-parthenocarpic tomato, and the proportion further declined to $24 \%$ in parthenocarpic tomato 3 weeks after anthesis.
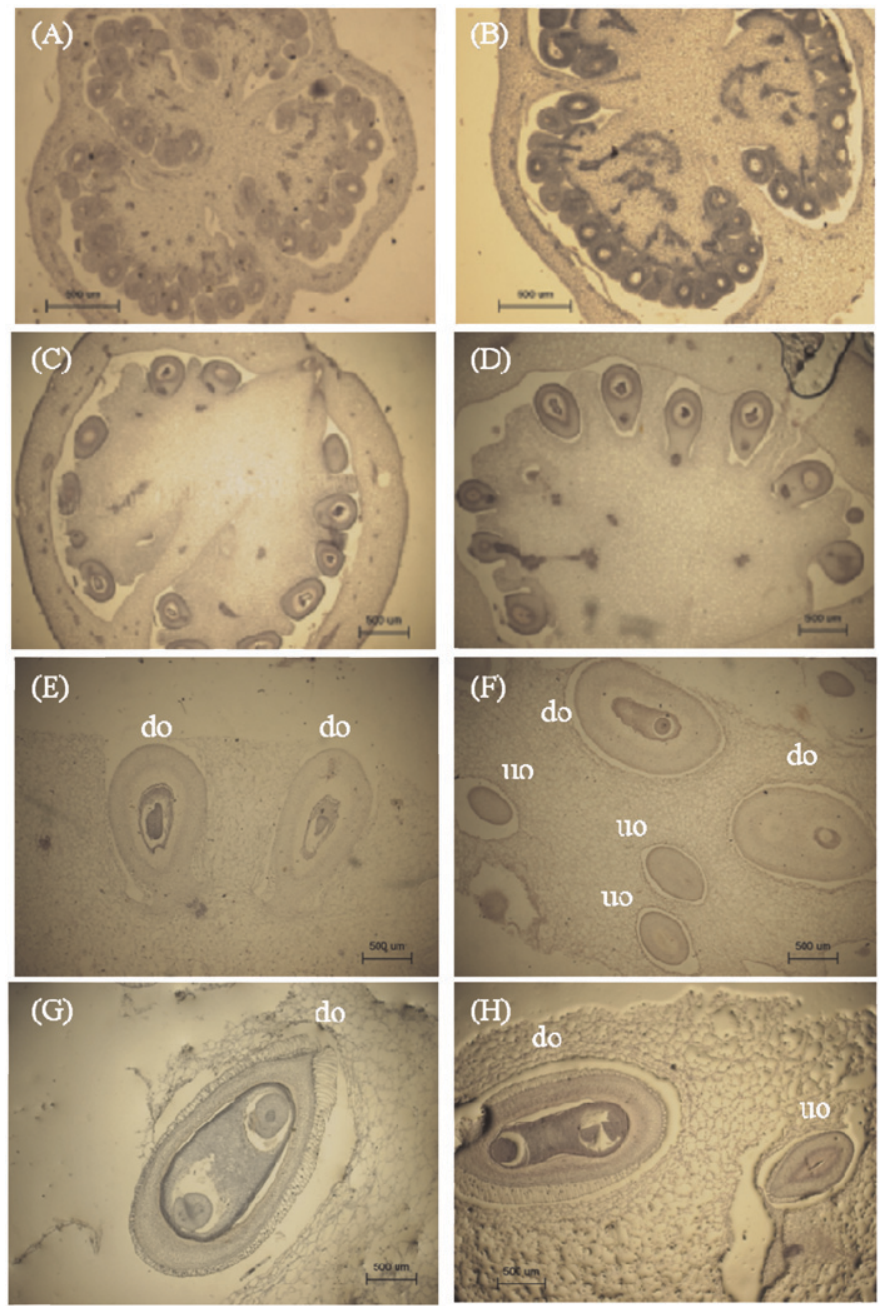

Fig. 2. Transverse sections of developing ovules in non-parthenocarpic (left) and parthenocarpic (right) tomato. Images are of ovaries at 0 weeks (A and $\mathbf{B})$, 1 week (C and D), 2 weeks ( $\mathbf{E}$ and $\mathbf{F})$, and 3 weeks ( $\mathbf{G}$ and $\mathbf{H})$ after anthesis. do $=$ developing ovule, uo $=$ undeveloped ovule.
Pollen tube elongation in STYle. At $72 \mathrm{~h}$ after pollination, penetration of pollen tubes in the style transmitting tissue in parthenocarpic and non-parthenocarpic tomato was examined by fluorescent microscopic observation (Fig. 4). Style in tomato has 3 to 5 transmitting tissue in the septum irrespective of genotype (Fig. 4). Pollen tubes were observed in transmitting tissue in the S1 (Fig. 4, A and B) and S4 (Fig. 4, C and D) style regions.

Arrival rate of pollen tubes in the S2 style region (Fig. 1) did not differ between parthenocarpic and non-parthenocarpic tomato (Fig. 5). However, only $21 \%$ of pollen tubes reached the $\mathrm{S} 3$ region in parthenocarpic tomato, which differed significantly from the high arrival rate $(72 \%)$ of pollen tubes in the S3

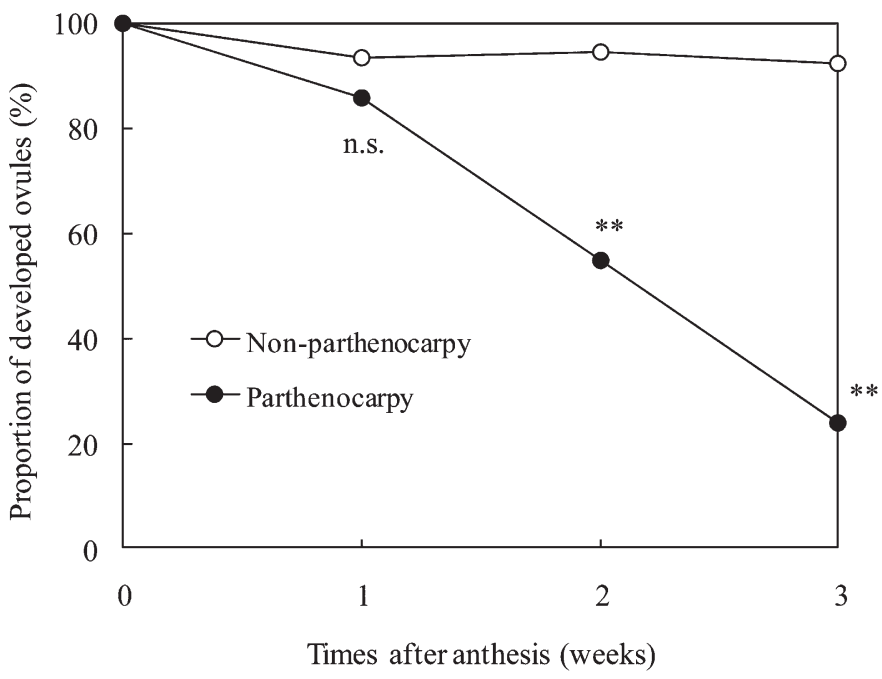

Fig. 3. Proportion of developed ovules in non-parthenocarpic and parthenocarpic tomato; ** indicates significance at $P=0.01$ by Student's $t$ test.
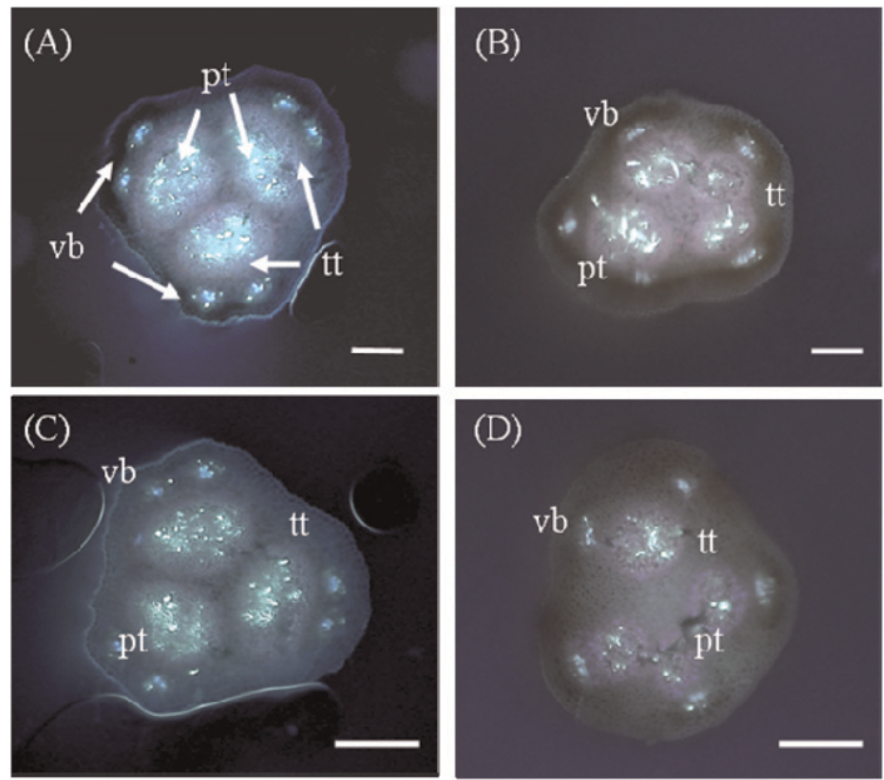

Fig. 4. Pollen tubes in style of non-parthenocarpic (left) and parthenocarpic (right) tomato $72 \mathrm{~h}$ after pollination. Transverse sections of the S1 (A and B) and S4 (C and D) regions of the style were stained with aniline blue and viewed with fluorescence microscopy. $\mathrm{pt}=$ pollen tube, $\mathrm{vb}=$ vascular bundle, $\mathrm{tt}=$ transmitting tissue, bars $=100 \mu \mathrm{m}$. 


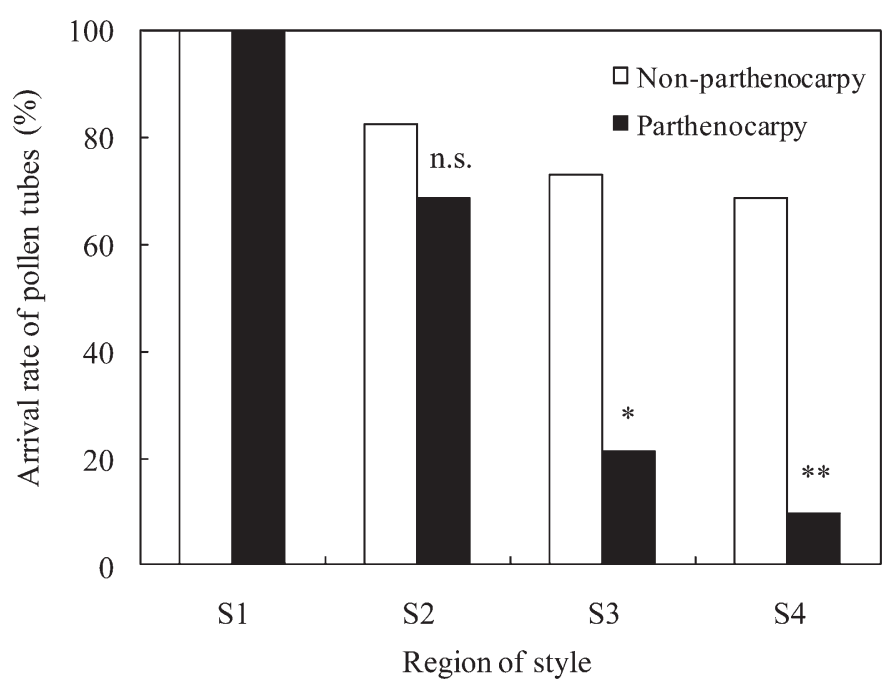

Fig. 5. Arrival rate of pollen tubes in different regions (S1-S4) of the style in non-parthenocarpic and parthenocarpic tomato $72 \mathrm{~h}$ after pollination; * and ** indicate significance at $P=0.05$ and 0.01 , respectively, by Student's $t$ test.

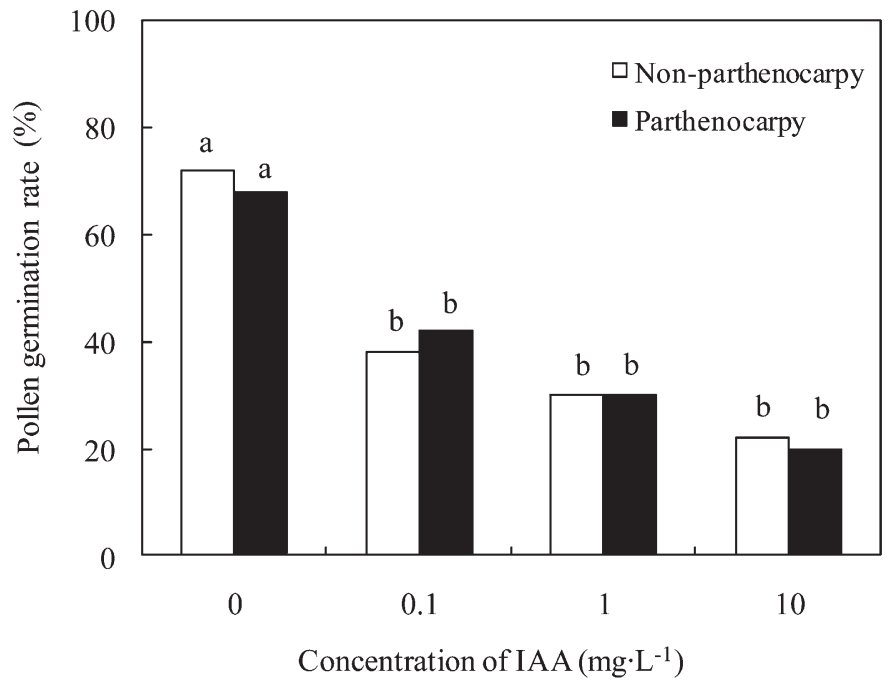

Fig. 6. Effect of IAA concentration on pollen grain germination in nonparthenocarpic and parthenocarpic tomato. Pollen grains were germinated on $0.8 \%$ agar containing IAA. The rate of pollen germination was measured $24 \mathrm{~h}$ after sowing. Different letters indicate a significance difference at $P=0.05$ with Tukey's multiple range tests.

region in non-parthenocarpic tomato. Only $10 \%$ of pollen tubes in parthenocarpic tomato reached the $\mathrm{S} 4$ region at the style base.

EFFECT OF INDOLEACETIC ACID ON POLLEN TUBE ELONGATION. At $24 \mathrm{~h}$ after sowing, the rate of pollen germination decreased with increasing IAA concentration in both types of tomato (Fig. 6).

The mean pollen tube length was $150 \mu \mathrm{m}$ in the absence of IAA but was significantly reduced by IAA in both tomato types $12 \mathrm{~h}$ after sowing (Fig. 7). Pollen tube elongation was increasingly inhibited with increasing IAA concentration $(\geq 1$ $\left.\mathrm{mg} \cdot \mathrm{L}^{-1}\right)$.

EFFECT OF P-CHLOROPHENOXYISOBUTYRIC ACID ON SEED SET IN PARTHENOCARPIC FRUIT. PCIB treatment did not affect the rate of fruit set $(100 \%)$ and the mean fruit fresh weight in parthenocarpic tomato (Table 2). PCIB treatment increased

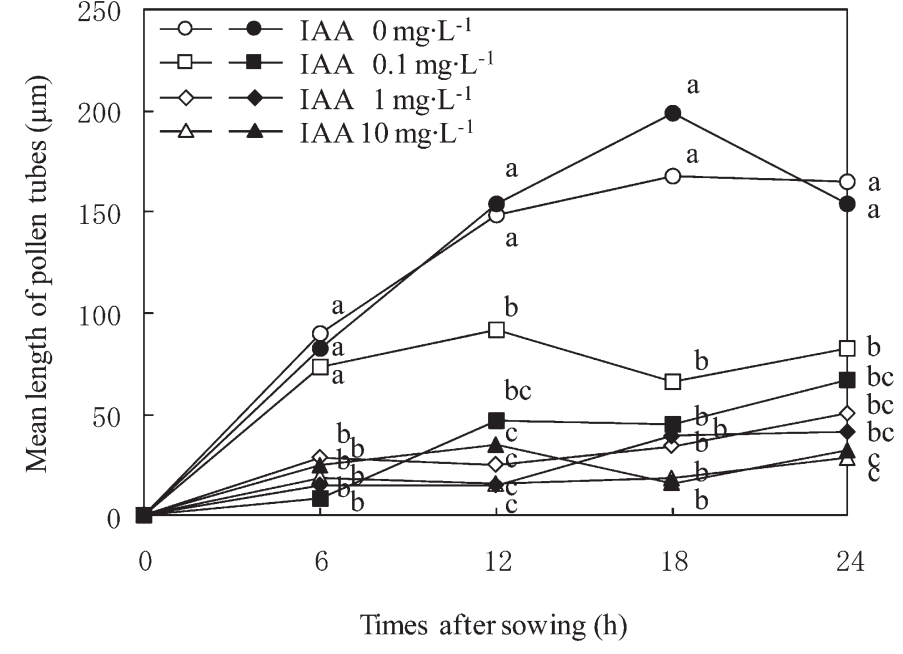

Fig. 7. Effect of IAA concentration on pollen tube elongation in nonparthenocarpic $(\bigcirc)$ and parthenocarpic $(\bullet)$ tomato. Pollen grains were sown on $0.8 \%$ agar containing IAA. Different letters above symbols at each time point indicate a significant difference at $P=0.05$ with Tukey's multiple range tests.

seed set per fruit in parthenocarpic tomato from $83 \%$ to $92 \%$, and the seed number per fruit was significantly increased from $13 \pm 2$ to $74 \pm 6$ seeds. The greater seed number (mean of 74 seeds) of parthenocarpic tomato in response to PCIB treatment was almost one-half the seed number (mean of 152 seeds) of non-parthenocarpic tomato.

\section{Discussion}

In most fruit, normal ovary growth requires the presence of seeds (Nitsch, 1970), and seeds play an important role in normal fruit development (Srivastava and Handa, 2005). Fruit fresh weight in non-parthenocarpic tomato was proportional to the number of seeds per fruit (Groot and Karssen, 1987) because development of the ovary requires plant growth regulations originating from the seeds (Sponsel, 1983; Talon et al., 1990; Rodrigo et al., 1997). In parthenocarpic tomato, the ovary is able to develop without ovule fertilization because the ovary synthesizes high levels of plant growth regulation (Fos et al., 2000, 2001; George et al., 1984; Mapelli et al., 1978; Olimpieri et al., 2007; Pandolfini et al., 2002), and few or no seeds were formed in fruit of normal fresh weight (Carmi et al., 2003). However, the number of ovules at anthesis did not differ between parthenocarpic and non-parthenocarpic tomato in our experiment. These results indicated that developmental arrest of ovules might account for the absence of seed maturation in parthenocarpic tomato.

In the present study, ovule morphology in the parthenocarpic tomato was normal at anthesis, but most ovules failed to develop after pollination. In the pat tomato mutant, the majority of ovules remained undeveloped and failed to increase in size after anthesis, and a fraction of ovules became aberrant from very early stages before anthesis (Mazzucato et al., 1998). Moreover, pollen tubes in pat and pat-2 tomato were disorientated in the ovarian cavity and often failed to adhere to the placental surface (Mazzucato et al., 2003). Mazzucato et al. (2003) considered that disorientated pollen tubes in the ovarian cavity were caused by aberrant ovules, which not only lack attractiveness, but disrupt pollen tube guidance overall. In this study, aberrant ovules were 
Table 2. Effect of $p$-chlorophenoxyisobutyric acid (PCIB) on fruit set, fruit fresh weight, and seed set and seeds number per fruit in parthenocarpic and non-parthenocarpic tomato plants.

\begin{tabular}{|c|c|c|c|c|c|}
\hline Type & $\begin{array}{l}\text { PCIB conc } \\
\left(\mathrm{mg} \cdot \mathrm{L}^{-1}\right)\end{array}$ & $\begin{array}{c}\text { Fruit set }^{\mathrm{z}} \\
(\%)\end{array}$ & $\begin{array}{c}\text { Fruit fresh wt } \\
{[\text { mean } \pm \mathrm{SE}(\mathrm{g})]}\end{array}$ & $\begin{array}{l}\text { Seed set }{ }^{\mathrm{y}} \\
(\%)\end{array}$ & $\begin{array}{c}\text { Seeds } \\
{[\text { mean } \pm \mathrm{SE} \text { (no./fruit) }]}\end{array}$ \\
\hline Non-parthenocarpy & - & 87 & $180 \pm \mathrm{a}^{\mathrm{x}}$ & 100 & $152 \pm \mathrm{a}$ \\
\hline \multirow[t]{2}{*}{ Parthenocarpy } & 0 & 100 & $167 \pm \mathrm{a}$ & 83 & $13 \pm c$ \\
\hline & 100 & 100 & $164 \pm \mathrm{a}$ & 92 & $74 \pm b$ \\
\hline
\end{tabular}

${ }^{\mathrm{z}}$ Fruit set was calculated by fruit per artificially pollinated flower.

${ }^{\mathrm{y}}$ Seed set was calculated by fruit with seed per all fruit.

'Same letters in each column indicate no difference with Tukey's multiple range test at the 0.05 significance level.

not observed at anthesis, but disorientated pollen tubes, such as those in the pat tomato mutant, might occur also in the parthenocarpic tomato with pat-2.

Low seed set in Cornus florida, Hydrangea paniculata, and Hydrangea quercifolia, which are self-incompatible, was induced by inhibition of pollen tube elongation (Reed, 2004a, 2004b). In tetraploid grape (Vitis vinifera), poor set of seeded berries in most tetraploid grapes was due to poor development of transmitting tissue in the septum, which severely inhibited pollen tube penetration into the micropyle (Okamoto et al., 2001). In this study, the morphology of transmitting tissue was no different between parthenocarpic and non-parthenocarpic tomato. In addition, seed development in pat-2 parthenocarpic tomato was affected by the maternal parent irrespective of the pollen parent, and the seeds tended to remain undeveloped when the ovary parent was parthenocarpic (Ohkawa et al., 2008). Because pollen tube elongation in the style was inhibited near the style base in parthenocarpic tomato, it is conceivable that a factor induces inhibition of pollen tube elongation close to the style base in parthenocarpic tomato.

Auxin plays an important role in the development of parthenocarpy (Gorguet et al., 2005). The expression of genetic parthenocarpy is correlated with the accumulation of auxins in the ovaries, which is autonomous and precocious compared with the respective wild types (George et al., 1984; Ikeda et al., 1999; Mapelli et al., 1978; Pandolfini et al., 2002). It was considered that the concentration of the endogenous auxin, IAA, at the base of the style may be higher than that near the stigma, and a high level of IAA may inhibit the growth of pollen tubes in parthenocarpic tomato. In our experiment, pollen tube elongation was inhibited by at least $0.1 \mathrm{mg} \cdot \mathrm{L}^{-1} \mathrm{IAA}$. The concentration of IAA in pat mutant parthenocarpic and nonparthenocarpic tomato fruit at anthesis was 0.16 and 0.05 $\mathrm{mg} \cdot \mathrm{kg}^{-1}$ fresh weight, respectively (Mapelli et al., 1978).

In our experiment, PCIB, which is described as an antiauxin or an auxin antagonist (Foster et al., 1995; Kim et al., 2000) and inhibitor of auxin action by binding to the auxin receptor site (MacRae and Bonner, 1953), increased the number of seeds in parthenocarpic tomato. Moreover, 2,3,5-triiodobenzonic acid, which is considered an antiauxin (Katayama and Marumo, 1994) or inhibitor of auxin transport (Christie and Leopold, 1965), increased the IAA concentration in the ovary and reduced the number of seeds in non-parthenocarpic tomato (Hamamoto et al., 1998). These results indicated that a reduced concentration of IAA in the ovary of parthenocarpic tomato in response to PCIB treatment allowed seed set, and therefore, the ovules in parthenocarpic tomato were normally developed, similar to those of non-parthenocarpic tomato. As parthenocarpic tomato formed pseudoembryos, which formed in the ovule cavity
(Kataoka et al., 2003), and aberrant ovules (Mazzucato et al., 2003), abnormal or arrested development of ovules in parthenocarpic tomato may be caused by autointoxication of auxin.

The number of seeds in parthenocarpic tomato was promoted by PCIB treatment, but was still less than that of nonparthenocarpic tomato. Fos et al. (2000) reported that parthenocarpy induced by the pat-2 gene was a response to increased synthesis of active GAs. The concentration of GAs in the ovary of non-parthenocarpic tomato was lower than that in pat (Olimpieri et al., 2007), pat-2 (Fos et al., 2000), and pat-3/pat-4 (Fos et al., 2001) parthenocarpic tomato. Several authors have reported that active GAs induced the development of seedless fruit (Bunger-Kibler and Bangerth, 1982; Sjut and Bangerth, 1982; Fos et al., 2000), and auxin increase the active GAs content in the fruit by unregulating genes encoding enzymes of GAs biosynthesis (Ross et al., 2000; Serrani et al., 2008). It is presumable that a high level of active or inactive GAs also inhibited seed development in parthenocarpic tomato.

This study showed that a high concentration of IAA inhibited the elongation of pollen tubes at the style base in pat-2 parthenocarpic tomato, resulting in poor fertilization and failure of ovule development. As floral organs in pat-2 parthenocarpic tomato were normally developed, seed development could be induced in pat-2 parthenocarpic tomato by PCIB treatment. Parthenocarpy is mainly used for crops where seedless fruit are desired by consumers (Varoquaux et al., 2000). In tomato, parthenocarpy could be useful as an answer to global warming. However, the price of seed in parthenocarpic tomato was more expensive than that of non-parthenocarpic tomato because of seedless, and it restricted the distribution of parthenocarpic tomato. Therefore, it is absolutely essential to control the effect of PCIB on seed formation in other genotypes of tomato parthenocarpic such as pat and pat-3/pat-4 genes. New or improved method by which seed formation in parthenocarpic tomato was induced more than by that in this study was needed.

\section{Literature Cited}

Bunger-Kibler, S. and F. Bangerth. 1982. Relationship between cell number, cell size and fruit size of seeded fruit of tomato (Lycopersicon esculentum Mill.), and those induced parthenocarpically by the application of plant growth regulators. Plant Growth Regulat. 1:143154.

Carmi, N., Y. Salts, B. Dedicova, S. Shabtai, and R. Barg. 2003. Induction of parthenocarpy in tomato via specific expression of the rolB gene in the ovary. Planta 217:726-735.

Christie, A.E. and A.C. Leopold. 1965. On the manner of triiodobenzoic acid inhibition of auxin transport. Plant Cell Physiol. 6:337-345.

Ficcadenti, N., S. Sestili, T. Pandolfini, C. Cirillo, G. Rotino, and A. Spena. 1999. Genetic engineering of parthenocarpic fruit development in tomato. Mol. Breed. 5:463-470.

Fos, M. and F. Nuez. 1996. Molecular expression of genes involved in parthenocarpic fruit set in tomato. Physiol. Plant. 98:165-171.

Fos, M. and F. Nuez. 1997. Expression of genes associated to natural parthenocarpy in tomato ovaries. J. Plant Physiol. 151:235-238.

Fos, M., F. Nuez, and J.L. García-Martínez. 2000. The gene pat-2, which induces natural parthenocarpy, alters the gibberellin content in unpollinated tomato ovaries. Plant Physiol. 122:471-479. 
Fos, M., K. Proano, D. Alabadi, F. Nuez, J. Carbonell, and J.L. GarcíaMartínez. 2003. Polyamine metabolism is altered in unpollinated parthenocarpic pat-2 tomato ovaries. Plant Physiol. 131:359-366.

Fos, M., K. Proano, F. Nuez, and J.L. García-Martínez. 2001. Role of gibberellins in parthenocarpic fruit development induced by the genetic system pat-3/pat-4 in tomato. Physiol. Plant. 111:545-550.

Foster, R.J., D.H. McRae, and J. Bonner. 1995. Auxin-antiauxin interaction at high auxin concentrations. Plant Physiol. 30:323-327.

Geisenberg, C. and K. Stewart. 1986. Field crop management, p. 511557. In: J.G. Atherton and J. Rudich (eds.). The tomato crop, Chapman \& Hall, London.

George, W.L., J.W. Scott, and W.E. Splittstoesser. 1984. Parthenocarpy in tomato. Hort. Rev. (Amer. Soc. Hort. Sci.) 6:65-84.

Gillaspy, G., H. Ben-David, and W. Gruissem. 1993. Fruits: A developmental perspective. Plant Cell 5:1439-1451.

Gorguet, B., A.W. van Heusden, and P. Lindhout. 2005. Parthenocarpic fruit development in tomato. Plant Biol. 7:131-139.

Groot, S.P.C. and C.M. Karssen. 1987. Gibberellins regulate seed germination in tomato by endosperm weakening: A study with gibberellin-deficient mutants. Planta 171:525-531.

Hamamoto, H., Y. Shishido, S. Furuya, and K. Yasuba. 1998. Growth and development of tomato fruit as affected by 2,3,5-triiodobenzoic acid (TIBA) applied to the peduncle. J. Jpn. Soc. Hort. Sci. 67:210-212.

Ikeda, T., H. Yakushiji, M. Oda, A. Taji, and S. Imada. 1999. Growth dependence of ovaries of facultatively parthenocarpic eggplant in vitro on indole-3-acetic acid content. Scientia Hort. 79:143-150.

Johkan, M., G. Mori, K. Mitsukuri, K. Mishiba, T. Morikawa, Y. Imahori, and M. Oda. 2008. Effect of ascorbic acid on in vivo organogenesis in tomato plants. J. Hort. Sci. Biotechnol. 83:624-628. Kataoka, K., A. Uemachi, and S. Yazawa. 2003. Fruit growth and pseudoembryo development affected by uniconazole, an inhibitor of gibberellin biosynthesis, in pat-2 and auxin-induced parthenocarpic tomato fruit. Scientia Hort. 98:9-16.

Kataoka, K., A. Uemachi, M. Nonaka, and S. Yazawa. 2004. Effect of endogenous gibberellins in the early stages of fruit growth and development of the 'Severianin' tomato. J. Hort. Sci. Biotechnol. 79:54-58.

Katayama, M. and S. Marumo. 1994. Antiauxin, p. 310-315. In: N. Takahashi and Y. Masuda (eds.). Handbook of plant hormones, Baifukan, Tokyo. (In Japanese).

Kim, S.K., S.C. Chang, E.J. Lee, W.S. Chung, Y.S. Kim, S. Hwang, and J.S. Lee. 2000. Involvement of brassinosteroids in the gravitropic response of the primary root of maize. Plant Physiol. 123:9971004.

Koshioka, M., T. Nishijima, H. Yamazaki, Y. Liu, M. Nonaka, and L.M. Mander. 1994. Analysis of gibberellins in growing fruits of Lycopersicon esculentum after pollination or treatment with 4chlorophenoxyacetic acid. J. Hort. Sci. 69:171-179.

Lukyanenko, A.N. 1991. Parthenocarpy in tomato, p. 167-178. In: G. Kalloo (ed.). Genetic improvement of tomato. Monographs on theoretical and applied genetics 14. Springer-Verlag, Berlin.

MacRae, D.H. and J. Bonner. 1953. Chemical structure and antiauxin activity. Physiol. Plant. 6:485-510.

Mapelli, S., C. Frova, G. Torti, and G.P. Soressi. 1978. Relationship between set, development and activities of growth regulators in tomato berries. Plant Cell Physiol. 19:1281-1288.

Mazzucato, A., A.R. Taddei, and G.P. Soressi. 1998. The parthenocarpic fruit (pat) mutant of tomato (Lycopersicon esculentum Mill.) sets seedless fruits and has aberrant anther and ovule development. Development 125:107-114.

Mazzucato, A., I. Olimpieri, F. Ciampolini, M. Cresti, and G.P. Soressi. 2003. A defective pollen-pistil interaction contributes to hamper seed set in the parthenocarpic fruit tomato mutant. Sex. Plant Reprod. 16:157-164.
Nitsch, J. 1970. Hormonal factors in growth and development, p. 427472. In: A.C. Hulme (ed.). The biochemistry of fruits and their products, Vol. II. Academic Press, London.

Ohkawa, H., S. Sugawara, and K. Yabe. 2008. Effects of crossing parents and artificial crossing stage on seed development of parthenocarpic tomato. Hort. Res. 7:445-449 (In Japanese with English abst.).

Okamoto, G., H. Tada, and K. Hirano. 2001. Poor development of transmitting tissue in tetraploid grape pistils causing inhibition if pollen tube growth. Vitis 40:49-54.

Olimpieri, I., F. Siligato, R. Caccia, L. Mariotti, N. Ceccarelli, G.P. Soressi, and A. Mazzucato. 2007. Tomato fruit set driven by pollination or by the parthenocarpic fruit allele are mediated by transcriptionally regulated gibberellin biosynthesis. Planta 226:877888.

Pandolfini, T., G.L. Rotino, S. Camerini, R. Defez, and A. Spena. 2002. Optimisation of transgene action at the post-transcriptional level: High-quality parthenocarpic fruits in industrial tomatoes. BMC Biotechnol. 2:1-11.

Peet, M.M. and M. Bartholomew. 1996. Effect of night temperature on pollen characteristics, growth and fruit set in tomato. J. Amer. Soc. Hort. Sci. 121:514-519.

Reed, S.M. 2004a. Self-incompatibility and time of stigma receptivity in two species of Hydrangea. HortScience 39:312-315.

Reed, S.M. 2004b. Self-incompatibility in Cornus florida. HortScience 39:335-338.

Rodrigo, M.J., J.L. García-Martínez, C.M. Santes, P. Gaskin, and P. Hedden. 1997. The role of gibberellins A1 and A3 in fruit growth of Pisum sativum L. and the identification of gibberellins A4 and A7 in young seeds. Planta 201:446-455.

Ross, J.J., D.P. O’Neil, J.J. Smith, H.J. Kerckhoffs, and R.C. Elliot. 2000. Evidence that auxin promotes gibberellin A1 biosynthesis in pea. Plant J. 21:547-552.

Sato, S., M. Kamiyama, T. Iwata, N. Makita, H. Furukawa, and H. Ikeda. 2006. Moderate increase of mean daily temperature adversely affects fruit set of Lycopersicon esculentum by disrupting specific physiological processes in male reproductive development. Ann. Bot. (Lond.) 97:731-738.

Sato, S., M.M. Peet, and J.F. Thomas. 2002. Determining critical preand post-anthesis periods and physiological processes in Lycopersicon esculentum Mill. exposed to moderately elevated temperatures. J. Expt. Bot. 53:1187-1195.

Serrani, J.C., M. Fos, A. Atarés, and J.L. García-Martínez. 2007. Effect of gibberellin and auxin on parthenocarpic fruit growth induction in the cv Micro-Tom of tomato. J. Plant Growth Regul. 26:211-221.

Serrani, J.C., O. Ruiz-Rivero, M. Fos, and J.L. García-Martínez. 2008. Auxin-induced fruit-set in tomato is mediated in part by gibberellins. Plant J. 56:922-934.

Sjut, V. and F. Bangerth. 1982. Induced parthenocarpy: A way of changing the levels of endogenous hormones in tomato fruits (Lycopersicon esculentum Mill.): 1. Extractable hormones. Plant Growth Regulat. 1:243-251.

Sponsel, V.M. 1983. The localization, metabolism and biological activity of gibberellins in maturing and germinating seeds of Pisum sativum cv. Progress No. 9. Planta 159:454-468.

Srivastava, A. and A.K. Handa. 2005. Hormonal regulation of tomato fruit development: A molecular perspective. J. Plant Growth Regul. 24:67-82.

Talon, M., P. Hedden, and E. Primo-Millo. 1990. Gibberellins in Citrus sinensis: A comparison between seeded and seedless varieties. J. Plant Growth Regul. 9:201-206.

Varoquaux, F., R. Blanvillain, M. Delseny, and P. Gallois. 2000. Less is better: New approaches for seedless fruit production. Trends Biotechnol. 18:233-242. 